\title{
PRECEDÊNCIA DA FONTE DE CUSTEIO COMO ELEMNTO INDISPENSÁVEL PARA A APOSENTADORIA ESPECIAL: UMA ANÁLISE DO LEADING CASE ARE664335
}

\author{
PRECEDENCE OF THE SOURCE OF FUNDING AS ESSENTIAL ELEMENT FOR \\ SPECIAL RETIREMENT: AN ANALYSIS OF LEADING CASE ARE664335
}

Antonio Bazilio Floriani Neto

Mestre direito em econômico pela PUCPR. Membro da Comissão de Direito Previdenciário da OAB-PR. E-mail: antonio@melissafolmann.com.br

Recebido em: 19.05.2014

Aprovado em: 19.02.2016

DOI: $10.5585 /$ rdb.v12i5.162

\section{Resumo}

O estudo insere-se no campo do direito constitucional, tributário e previdenciário. Analisar-se-á a questão levada ao Supremo Tribunal Federal no ARE 664335, cuja decisão poderá colocar em risco a aposentadoria especial. Esta prestação é destinada ao segurado que tenha trabalhado exposto a agentes nocivos e é concedida quando confirmado o exercício do ofício em condições adversas por 15, 20 ou 25 anos. Para fazer jus a este benefício, atualmente exige-se a comprovação da efetiva exposição do trabalhador por meio do formulário denominado perfil profissiográfico. Defende a Previdência Social no ARE 664335 que se houver no perfil profissiográfico a informação acerca da eficácia dos equipamentos de proteção individual, não deve ser concedida a aposentadoria, sob pena de ofender a precedência da fonte de custeio. Neste passo, a proposta do artigo é examinar os possíveis efeitos da decisão do STF, caso sejam aceitos os argumentos do INSS. Para tanto, será dado enfoque aos argumentos tributários, passando-se pela natureza jurídica das contribuições sociais, pelo seu cunho finalístico, pelas fontes de financiamento da Previdência Social. Também será utilizado o arcabouço fornecido pela Análise Econômica, o que sugere um cenário bastante desfavorável ao segurado, em que a assimetria informacional poderá levar a um ambiente de risco moral e seleção adversa

Palavras-chave: Direitos fundamentais. Direito tributário. Aposentadoria especial. Análise Econômica do Direito. Jurisprudência.

\footnotetext{
Abstract

The study falls within the field of constitutional, tax and social security law. Will be analyzed a Supreme Court case in the ARE 664 335, which may affect an important social right: the special retirement. This pension is aimed for the insured
} 
who has worked exposed to harmful agents and is granted where the exercise proven craft in adverse conditions for 15,20 or 25 years. To do justice to this provision, currently requires the corroboration of actual worker exposure through the form called professional profile. Social Security advocates that if the professional profile information about the effectiveness of personal protective equipment, retirement should not be granted, under penalty of offending the precedence of the source of funding. In this step, the aim of this work is to examine the possible effects of the Supreme Court decision, if the arguments of the INSS are accepted. In this context, focus will be given to tax arguments passing by the legal nature of social contributions for its finalistic nature, the sources of financing of Social Security. Also the framework provided by the Economic Analysis, which suggests a very unfavorable scenario for the insured, in which information asymmetry can lead to an environment of moral hazard and adverse selection will be used.

Keywords: Fundamental rights. Tax Law. Especial Retirement. Economic Analysis of Law. Jurisprudence.

\section{Introdução}

Os direitos sociais estão inseridos, dentro da dicotomia dos direitos fundamentais, como sendo de segunda dimensão, podendo ser caracterizados por sua dimensão positiva (SARLET, 2008, p. 55), ou seja, consistem em um agir do aparelho estatal.

A preocupação com estes direitos dominou o século XX (BONAVIDES, 2004, p. 564), ganhando corpo no período pós-revolução industrial, quando os cidadãos já não mais conseguiram, de forma isolada, gozar de liberdade e igualdade.

Neste passo, as questões sociais e econômicas fizeram com que a concepção liberal do Estado fosse alterada para uma postura ativa, momento em que se fala do Welfare State. Esta alteração de paradigma possibilitou ao indivíduo buscar não a liberdade do e perante o Estado, mas por intermédio deste (SARLET, 2010, p. 55).

Por conta disso, Gilmar Ferreira Mendes (2011, p. 667) assevera que os direitos sociais representam um postulado de prevenção, consistindo tanto a prestações em sentido estrito, quanto aos direitos de defesa.

Em contrapartida, para que possam ser efetivados, se torna indispensável a utilização de recursos públicos (SCHAFER, 2005, p. 64), os quais advêm principalmente dos tributos (SCHOUERI, 2005, p. 1).

E é justamente nesta relação jurídico tributária onde reside a questão a ser enfrentada neste artigo. 
A Constituição Federal de 1988, em seu artigo $6^{\circ}$, definiu os direitos sociais como sendo aqueles inerentes à educação, saúde, alimentação, trabalho, moradia, lazer, segurança, previdência social, proteção à maternidade e à infância, bem como a assistência aos desamparados.

Para o presente trabalho, o enfoque será dado ao direito à previdência, que por força constitucional (art. 194) compõe a Seguridade Social brasileira. No que se refere ao financiamento, estabeleceu o artigo 195, da Lei das Leis, que será custeada por toda sociedade, através de contribuições sociais.

O artigo 201, por sua vez, trata especificamente da Previdência Social, estabelecendo o seu campo de abrangência e os riscos socais que atenderá. Além disso, o seu $\S 1^{\circ}$, foi expresso em impedir a adoção de critérios diferenciados para concessão de aposentadorias, exceto para dois casos: as atividades exercidas sob condições especiais e quando se tratar de segurados portadores de deficiência.

Com o reconhecimento da repercussão geral, pelo Supremo Tribunal Federal, no ARE 664335, observa-se a possível lesão à primeira das hipóteses mencionadas, qual seja: direito dos trabalhadores a aposentadoria especial por exercerem atividades expostas a agentes nocivos.

Trata-se, do tema de $\mathrm{n}^{\circ} 555$, cuja discussão envolve o fornecimento de Equipamento de Proteção Individual (EPI) como fator de descaracterização do tempo de serviço especial em que foram trazidos a baila o $\S 5^{\circ}$, do art. 195, bem como do $\S$

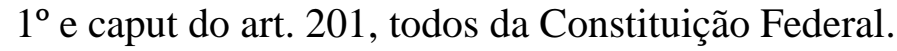

De uma maneira sucinta, a controvérsia gira em torno da precedência da fonte de custeio e aposentadoria especial, verificando-se, portanto, um confronto entre direito social e financiamento.

Dito isto, o objetivo deste artigo é analisar pormenorizadamente as razões e fundamentos que levaram o STF a determinar a repercussão geral desta matéria e em que medida pode ser afetada a eficácia do direito a aposentadoria especial, caso sejam aceitos os argumentos suscitados pelo Instituto Nacional do Seguro Social (INSS).

Para tanto, o primeiro item do estudo será voltado à aposentadoria especial: os requisitos, peculiaridades e documentos necessários para sua obtenção.

Tendo estes conceitos em mente, examinar-se-á o ARE 664335 e o tema número 555. 
Por fim, o último tópico terá como escopo confrontar o direito a aposentadoria especial e a discussão levantada junto ao STF sob o aspecto tributário, com a utilização do ferramental fornecido pela Análise Econômica do Direito (AED).

\section{2. $\mathrm{O}$ direito à aposentadoria especial}

A aposentadoria especial é um benefício previdenciário destinado ao segurado que tenha laborado em condições prejudicais a saúde ou a integridade física (RIBEIRO, 2013, p. 33). Justamente por conta desses prejuízos causados ao bem-estar físico do trabalhador, esta prestação exige um tempo de 15, 20 ou 25 anos de contribuição.

Nesta esteira, importante destacar outras duas peculiaridades desta prestação: de acordo com a legislação vigente (Lei 8.213/91) não há uma idade mínima para sua obtenção e sobre ela não há a incidência do famigerado fator previdenciário. Por conta disso, o benefício se torna atrativo, pois os segurados podem se aposentar novos e com uma prestação financeiramente vantajosa.

Em contrapartida, comprovar o trabalho em condições prejudicais não é uma tarefa simples para o cidadão. Para melhor compreender esta assertiva, torna-se imprescindível a análise do histórico da aposentadoria especial.

\subsection{Breve histórico}

A sua instituição no ordenamento jurídico pátrio ocorreu por meio da Lei 3.807/60, Lei Orgânica da Previdência Social - LOPS, em seu art. $31^{1}$.

De uma maneira sucinta, a mencionada Lei estabeleceu três requisitos para sua concessão: idade de 50 anos, carência $^{2}$ de 180 contribuições e um tempo de 15, 20 ou 25 anos de trabalho considerado como penoso, insalubre ou perigoso.

\footnotetext{
1 Art 31. A aposentadoria especial será concedida ao segurado que, contando no mínimo 50 (cinqüenta) anos de idade e 15 (quinze) anos de contribuições tenha trabalhado durante 15 (quinze), 20 (vinte) ou 25 (vinte e cinco) anos pelo menos, conforme a atividade profissional, em serviços, que, para êsse efeito, forem considerados penosos, insalubres ou perigosos, por Decreto do Poder Executivo.

$\S 1^{\circ}$ A aposentadoria especial consistirá numa renda mensal calculada na forma do $4^{\circ}$ do art. 27 , aplicando-se-lhe, outrossim o disposto no $\S 1^{\circ}$ do art. 20.

$\S 2^{\circ}$ Reger-se-á pela respectiva legislação especial a aposentadoria dos aeronautas e a dos jornalistas profissionais.

${ }^{2}$ Número mínimo de contribuições mensais indispensáveis para que o beneficiário faça jus ao benefício.
} 
Como a única das condições que poderia gerar controvérsias era a comprovação da insalubridade, do perigo ou da condição penosa do ofício, a Lei 3.807/60 estabeleceu que tal encargo regulamentar ficaria por conta de Decreto do Poder Executivo. Assim sendo, foi editado o Decreto 53.831/64 ${ }^{3}$, o qual fixou por meio de quadro anexo, um rol de agentes químicos, físicos e biológicos, bem como de serviços e atividades profissionais consideradas como insalubres, perigosas ou penosas.

Vale destacar que esta comprovação do tempo de serviço especial por enquadramento vigorou durante vários anos e sob dois critérios: por categoria profissional e por exposição a agentes nocivos.

Neste passo, para fazer jus à prestação, bastava que o segurado comprovasse o exercício de um ofício que lhe colocasse em condição insalubre, perigosa, penosa ou, então, em exposição aos agentes considerados nocivos.

Não era necessária a comprovação da efetiva exposição a agentes nocivos ou das condições prejudiciais à saúde, tratando-se de uma presunção de risco. Assim sendo, profissionais como o médico, o dentista, o torneiro mecânico, poderiam obter a aposentadoria especial caso comprovassem, única e exclusivamente, o exercício destes ofícios.

Este critério perdurou por muito tempo e sofreu significativa alteração com a Lei 9.032/95, que extingui a presunção de risco, conforme entendimento pacífico da jurisprudência pátria ${ }^{4}$.

\footnotetext{
${ }^{3}$ Art. $^{\circ}$ A Aposentadoria Especial, a que se refere o art. 31 da Lei 3.807, de 26 de agosto de 1960, será concedida ao segurado que exerça ou tenha exercido atividade profissional em serviços considerados insalubres, perigosos ou penosos nos termos deste decreto.

Art. $2^{\mathbf{0}}$ Para os efeitos da concessão da Aposentadoria Especial, serão considerados serviços insalubres, perigosos ou penosos, os constantes do Quadro Anexo em que se estabelece também a correspondência com os prazos referido no art. 31 da citada Lei.

Art. $3^{\circ}$ A concessão do benefício de que trata este decreto dependerá de comprovação pelo segurado efetuado na forma prescrita pelo art. 60, do Regulamento Geral da Previdência Social, perante o Instituto de Aposentadoria e Pensões a que estiver filiado do tempo de trabalho permanente e habitualmente prestado no serviço ou serviços, considerados insalubres, perigosos ou penosos, durante o prazo mínimo fixado.

Art. $4^{\circ}$ Os institutos de Aposentadoria e Pensões enviarão semestralmente à Divisão de Higiene e Segurança do Trabalho, do Ministério do Trabalho e Previdência Social na forma do modelo a ser apresentado por essa Divisão relação das empresas que empregavam os segurados, a que tenha sido concedida aposentadoria especial.

Art. $5^{\circ}$ As dúvidas suscitadas na aplicação do presente Decreto serão resolvidas pelo Departamento Nacional da Previdência Social ouvida sempre a Divisão de Higiene e Segurança do Trabalho, no âmbito de suas atividades.

Art. $6^{\mathbf{0}}$ Este Decreto entra em vigor na data de sua publicação, revogadas as disposições em contrário.

${ }^{4}$ REsp 639.066/RJ, Rel. Ministro ARNALDO ESTEVES LIMA, QUINTA TURMA, julgado em 20.9.2005, DJ 7.11.2005 p. 345
} 
A contar da referida lei, portanto, não mais foi possível o enquadramento por categorial profissional ${ }^{5}$, tornando-se imprescindível a demonstração da exposição a agentes nocivos por qualquer meio de prova ${ }^{6}$.

Editado o Decreto $2.172 / 97^{7}$, foi quando se passou a exigir do segurado, para fazer jus ao tempo especial, a comprovação da efetiva sujeição por meio de formulário embasado em laudo técnico. Esta exigência, inclusive, está prevista na Lei 8.213/91, artigo 58, $\S 1^{\text {o8 }}$, cuja redação está vigente.

Tendo em vista todas estas alterações ocorridas, pode ser levantada a dúvida acerca de qual legislação aplicar ao caso em concreto, pois o segurado pode ter exercido condições especiais nos mais variados períodos, cada qual com vigência de uma lei distinta. Para dirimir esta inquietação, a jurisprudência tem assim se pronunciado:

O reconhecimento da especialidade da atividade exercida é disciplinado pela lei em vigor à época em que efetivamente exercido, passando a integrar, como direito adquirido, o patrimônio jurídico do trabalhador. Desse modo, uma vez prestado o serviço sob a égide de legislação que o ampara, o segurado adquire o direito à contagem como tal, bem como à comprovação das condições de trabalho na forma então exigida, não se aplicando retroativamente uma lei nova que venha a estabelecer restrições à admissão do tempo de serviço especial ${ }^{9}$.

Atualmente, portanto, para que o segurado obtenha a aposentadoria especial, deve comprovar 15, 20 ou 25 anos de exposição a agentes nocivos, consoante dispõe o artigo 57, da Lei $8.213 / 91^{10}$, independentemente da idade. Ademais, a legislação

\footnotetext{
${ }^{5}$ Com exceção daquelas atividades a que se refere a Lei $n .^{\circ} 5.527 / 68$, cujo enquadramento por categoria deve ser feito até 13/10/1996, dia anterior à publicação da Medida Provisória n. ${ }^{\circ} 1.523$, de 14-10-1996, como por exemplo ocorre com os engenheiros.

${ }^{6}$ Conforme a consolidada jurisprudência do TRF4 (TRF4 5009435-60.2012.404.7204, Quinta Turma, Relator p/ Acórdão Ricardo Teixeira do Valle Pereira, D.E. 07/05/2013 e TRF4 503424154.2010.404.7100, Sexta Turma, Relator p/ Acórdão Celso Kipper, D.E. 27/09/2013).

${ }^{7}$ Este decreto trouxe alterações no artigo 58, da Lei 8.213/91, que foram efetivadas por meio da Lei 9.528/97.

${ }^{8}$ Art. 58. A relação dos agentes nocivos químicos, físicos e biológicos ou associação de agentes prejudiciais à saúde ou à integridade física considerados para fins de concessão da aposentadoria especial de que trata o artigo anterior será definida pelo Poder Executivo.

$\S 1^{\circ}$ A comprovação da efetiva exposição do segurado aos agentes nocivos será feita mediante formulário, na forma estabelecida pelo Instituto Nacional do Seguro Social - INSS, emitido pela empresa ou seu preposto, com base em laudo técnico de condições ambientais do trabalho expedido por médico do trabalho ou engenheiro de segurança do trabalho nos termos da legislação trabalhista (grifo nosso).

9 TRF4, APELREEX 5000895-84.2011.404.7001, Sexta Turma, Relator p/ Acórdão Celso Kipper, D.E. 27/09/2013. Neste sentido também está a jurisprudência do STJ, ver AgRg no REsp 1.103.602/RS,, SEXTA TURMA, DJe 3/8/2009.

${ }^{10}$ Art. 57. A aposentadoria especial será devida, uma vez cumprida a carência exigida nesta Lei, ao segurado que tiver trabalhado sujeito a condições especiais que prejudiquem a saúde ou a integridade física, durante 15 (quinze), 20 (vinte) ou 25 (vinte e cinco) anos, conforme dispuser a lei.
} 
vigente exige do segurado a comprovação da efetiva exposição através de laudos e formulários.

Examinado o histórico da aposentadoria especial e seus requisitos, passa-se à questão do seu financiamento.

\subsection{Financiamento}

O artigo 57, $\S 6^{\circ 11}$, da Lei 8.213/91, estipula que a aposentadoria especial será financiada com recursos oriundos do seguro de acidentes do trabalho (SAT), previsto no artigo 22, da Lei 8.212/91.

Esta contribuição, conforme expressa previsão legal, fica a cargo da empresa e incide sobre o total de remuneração paga ou creditada, no decorrer do mês.

Outro aspecto relevante do SAT é o dever da empresa em pagá-lo não apenas para os seus empregados, como também para aqueles trabalhadores que lhe prestam serviços.

Ademais, conforme se observa na Lei 8.212, a empresa pagará um maior tributo com base no risco da atividade preponderante e a sua capacidade potencial para ocasionar acidentes de trabalho: caso seja considerado leve, a alíquota será de $1 \%$, ao passo que o risco médio implica na alíquota de $2 \%$ e a maior, de $3 \%$, aplica-se para os riscos considerados graves.

Diante disso, tem-se que o tempo reduzido para obtenção da aposentadoria especial encontra custeio na medida em que a empresa, responsável tributária pelo recolhimento, é incumbida de uma maior contribuição. Em certa medida houve uma inversão da posição do risco que antes era presumido em desfavor do agente pagador (INSS) e que agora passa a ser da empresa empregadora, mas também sobre uma presunção que não confere um critério adequado e preciso acerca das responsabilidades e das atividades enquadradas.

Vejamos, agora, o leading case ARE 664335.

\footnotetext{
${ }^{11}$ Art. 57. A aposentadoria especial será devida, uma vez cumprida a carência exigida nesta Lei, ao segurado que tiver trabalhado sujeito a condições especiais que prejudiquem a saúde ou a integridade física, durante 15 (quinze), 20 (vinte) ou 25 (vinte e cinco) anos, conforme dispuser a lei.

[...]

\$ $\mathbf{6}^{\circ} \mathrm{O}$ benefício previsto neste artigo será financiado com os recursos provenientes da contribuição de que trata o inciso II do art. 22 da Lei $\mathrm{n}^{\circ}$ 8.212, de 24 de julho de 1991, cujas alíquotas serão acrescidas de doze, nove ou seis pontos percentuais, conforme a atividade exercida pelo segurado a serviço da empresa permita a concessão de aposentadoria especial após quinze, vinte ou vinte e cinco anos de contribuição, respectivamente.
} 


\section{Repercussão geral, tema número 555 - Leading Case ARE 664335}

Em 14/06/2012, o ministro Luiz Fux, relator do recurso extraordinário com agravo ARE 664335, reconheceu a repercussão geral da discussão envolvendo o fornecimento de EPI como fator de descaracterização do tempo de serviço especial, entendendo que a questão era "[...] relevante do ponto de vista econômico, político, social e jurídico, e ultrapassa os interesses subjetivos da causa" (ARE 664335 RG, Relator(a): Min. LUIZ FUX, julgado em 14/06/2012, ACÓRDÃO ELETRÔNICO DJe-107 DIVULG 06-06-2013 PUBLIC 07-06-2013).

O primeiro aspecto que proclama atenção deste tema é aparente questão probatória que o envolve, eis que a eficácia do equipamento de proteção individual deveria restar comprovada para afastar o tempo especial.

Fosse esta a discussão, o recurso extraordinário com agravo não envolveria matéria de índole constitucional, mas probatória, de modo que jamais se enquadraria no artigo 102, $\S 3^{\circ}$, da Constituição de 1988. Destaca-se, inclusive, que o voto proferido pelo iminente ministro Marco Aurélio Mello foi neste sentido.

No entanto, entenderam os demais ministros do STF que o questionamento proposto pelo Instituto Nacional do Seguro Social foi embasado no artigo 195, $\S 5^{\circ} \mathrm{e}$ artigo 201, $\S 1^{\circ}$, ambos da Constituição de 1988.

Argumentou a autarquia previdenciária que o simples fato de a empresa mencionar, por meio de formulário $\mathrm{PPP}^{12}$, a eficácia do EPI, estariam elididos os riscos para o trabalhador. Como consequência, haveria uma redução no SAT contribuído pela empresa. Logo, o argumento do INSS é pela impossibilidade de conceder benefício sem a correspondente fonte de custeio, haja vista o princípio da preservação do equilíbrio financeiro e atuarial.

Verifica-se, portanto, que a Previdência Social vincula a concessão de aposentadoria especial ao pagamento do SAT pela empresa para custear as mencionadas prestações, conforme expressamente prevê a Lei 8.212/91, em seu artigo 22.

${ }^{12}$ Perfil Profissiográfico Previdenciário. 
Neste passo, se a empresa simplesmente deixar de cumprir com sua obrigação tributária e a Previdência, com o seu dever se fiscalização, poderá o segurado ser prejudicado com o seu direito a aposentadoria especial.

Há uma assimetria consequencial, pois a relação estabelecida não está amparada na premissa de causa e efeito, uma vez que associa consequências absolutamente desconexas. De fato, o direito a aposentadoria especial não pode depender do cumprimento da obrigação tributária ou a ação fiscalizatória do INSS.

Esse quadro leva a um processo natural de seleção adversa, em que, por exemplo, o INSS pode eleger como uma conduta preferencial não fiscalizar para buscar se eximir da responsabilidade pelo pagamento.

Por conta disso, acredita-se que a análise econômica do direito tributário pode ser aplicada à questão e assim chegar à conclusão de que podem ser afastados todos os argumentos que levariam a procedência do ARE 664335.

\section{Argumentos tributários}

O primeiro argumento no qual o INSS sustenta o seu recuso extraordinário diz respeito à natureza jurídica do SAT: uma contribuição de natureza tributária, que visa custear a aposentadoria especial.

Cabe destacar que a mencionada contribuição social está prevista constitucionalmente, no artigo 195, inciso I, § 9. A Constituição de 1988 estabeleceu a responsabilidade dos empregadores de financiar a seguridade social por meio do desconto em folha de salários e ainda estipulou que as alíquotas destas contribuições poderiam ter base de cálculo diferenciadas de acordo com a atividade econômica da empresa, da utilização intensiva da mão de obra, do porte da empresa ou da condição estrutural do mercado de trabalho.

Pensou o constituinte, portanto, em cobrar um tributo maior daquelas empresas que expusessem os seus trabalhadores a maiores riscos. Destaca-se, aqui, que o termo trabalhador é utilizado propositalmente, eis que a responsabilidade pela contribuição previdenciária abrange às pessoas físicas prestadoras de serviços, mesmo sem vínculo empregatício.

Pois bem, a Lei 8.212/91, em seu artigo 22, incisos I e II, conforme exposto no item 1.2, foi a responsável por dar a redação atual ao SAT, estabelecendo alíquotas diferenciadas com base no risco da atividade preponderante da empresa. 
Neste passo, entende a Previdência Social que o SAT é constitucional e tem um propósito específico: custear as aposentadorias especiais. Não bastasse isso, com o advento da Lei 10.666/2003, artigo 10, assevera o INSS que houve a possibilidade de redução das alíquotas do SAT com a criação do Fator Acidentário de Prevenção (FAP). Em linhas gerais, o FAP é um multiplicador que pode reduzir em até $50 \%$ ou aumentar em até $100 \%$ as mencionadas alíquotas.

Neste contexto, caso seja possível o reconhecimento da especialidade de um período mesmo com a informação de que o EPI foi eficaz, poderá, segundo o INSS, haver uma violação direta ao princípio do equilíbrio financeiro e atuarial.

No entanto, este argumento suscitado não deve prevalecer porque: (i) a Seguridade Social têm outras fontes de financiamento, diretas e indiretas e não somente o SAT; (ii) as contribuições sociais têm um cunho finalístico, ou seja, visam cobrir os riscos sociais; (iii) a mera informação da empresa de que o EPI é eficaz não elide o dever de fiscalização que recai ao INSS e, por fim, (iv) a procedência do ARE 664335, levará a criação de um ambiente de risco moral e seleção adversa, privilegiando os maus empregadores e reduzindo os custos de transação do INSS, levando a uma eficiência de Pareto, em que o único prejudicado será o segurado.

Passemos a analisar cada uma delas.

\subsection{Das fontes de custeio do sistema previdenciário brasileiro}

A Constituição Federal de 1988 reputou, de forma expressa, que a proteção jurídica previdenciária seria um direito do cidadão e um dever do Estado dentro do núcleo seguridade social, que por sua vez é financiada por toda sociedade de forma direta (cotizações) e indireta (transferência de recursos orçamentários da União, Estados, Distrito Federal e Municípios), conforme se verifica no artigo 195, abaixo transcrito:

Art. 195. A seguridade social será financiada por toda a sociedade, de forma direta e indireta, nos termos da lei, mediante recursos provenientes dos orçamentos da União, dos Estados, do Distrito Federal e dos Municípios, e das seguintes contribuições sociais:

I - do empregador, da empresa e da entidade a ela equiparada na forma da lei, incidentes sobre:

a) a folha de salários e demais rendimentos do trabalho pagos ou creditados, a qualquer título, à pessoa física que lhe preste serviço, mesmo sem vínculo empregatício;

b) a receita ou o faturamento; 


\begin{abstract}
c) o lucro;
II - do trabalhador e dos demais segurados da previdência social, não incidindo contribuição sobre aposentadoria e pensão concedidas pelo regime geral de previdência social de que trata o art. 201;

III - sobre a receita de concursos de prognósticos.

IV - do importador de bens ou serviços do exterior, ou de quem a lei a ele equiparar.
\end{abstract}

Esta escolha do constituinte nada mais foi do que um reflexo da ideia inicial introduzida acerca dos direitos sociais que consistem em um agir do aparelho estatal a fim de atenuar as desigualdades entre os indivíduos.

Caso a Constituição de 1988 tivesse adotado um sistema liberal clássico essa questão não surgiria. No entanto, a eleição de um sistema interventor, cujo objetivo é transformar a realidade (art. $3^{\circ}$ ) e implementar um Estado Democrático de Direito, não entende a relação previdenciária como uma tutela exclusiva do empregadoempregador, mas sim como uma necessidade-possibilidade, envolvendo o poder público.

Desse modo, ao contrário do que muitos imaginam, a seguridade social não é financiada somente pelas contribuições sociais, mas também por recursos provenientes União, dos Estados, do Distrito Federal e dos Municípios.

Há claramente uma repartição de responsabilidades constitucionalmente estipuladas de forma que sociedade e Estado devem contribuir para a existência e a manutenção da seguridade social.

Não bastasse isso, o $\S 4^{013}$, do artigo 195 , previu a possibilidade de instituir, mediante lei, outras fontes de custeio destinadas a manutenção ou a expansão da seguridade social.

Em sentido análogo está o artigo 250, também da Constituição de 1988, que autorizou a União criar um fundo integrado por bens, direitos e ativos de qualquer natureza que vise assegurar o pagamento dos benefícios concedidos pelo RGPS.

Em outros termos, se houver receita for suficiente para gerir o plano atual, podem ser criadas outras. Caliendo (2009, p. 341) ainda destaca que o orçamento da seguridade social representa parte substancial no orçamento federal das nações desenvolvidas, não sendo diferente no Brasil. O autor, amparado em estudos

\footnotetext{
${ }^{13} \S 4^{\text {o }}$ - A lei poderá instituir outras fontes destinadas a garantir a manutenção ou expansão da seguridade social, obedecido o disposto no art. 154, I.
} 
realizados em 1973 por Nancy H. Teeters, destacou que as contribuições sociais representavam a segunda fonte de recursos públicos arrecadados ${ }^{14}$.

Nesta linha de raciocínio, cabe destacar que o Estado brasileiro recentemente deu indícios de que o custeio para a Seguridade Social não é um problema, eis que desonerou a contribuição previdenciária patronal de $20 \%$ incidente sobre a folha de pagamento por intermédio da Lei 12.546/2011.

De acordo com um estudo realizado pela Associação Nacional dos Auditores Fiscais (ANFIP), a fórmula implementada pela lei ocasionou em um decréscimo de $\mathrm{R} \$ 7,06$ bilhões de reais em $2012^{15}$.

Neste passo, ao invés de criar mecanismos para aumentar a receitas, o exemplo ocorrido com a Lei 12.546/2011 está em sentido contrário. Esta redução de $\mathrm{R} \$ 7,06$ bilhões anuais, sim, poderia levar o desequilíbrio do sistema financeiro e atuarial, eis que representa um grande impacto econômico.

Assim, o primeiro argumento pelo qual não procede a insurgência no ARE 664335 é de que o Estado tem diversas fontes para custear os benefícios previdenciários, podendo, inclusive, criar meio arrecadatórios arrecadação, caso entenda necessário.

Nesta esteira, não são as contribuições sociais dos empregadores o único meio para financiamento da Previdência Social e, ainda que assim o fosse, há o critério finalístico das contribuições sociais, sendo este o segundo argumento trazido, conforme doravante se expõe.

\subsection{Natureza jurídica das contribuições sociais}

Ataliba (2010, p. 152) define contribuição como sendo um "tributo vinculado cuja hipótese de incidência consiste numa atuação estatal indireta e mediatamente (mediante uma circunstância intermediária) referida ao obrigado".

As contribuições podem ser das mais variadas espécies, mas no presente caso focaremos nas sociais. Assim sendo, torna-se indispensável a análise da natureza

\footnotetext{
${ }^{14}$ TEETERS, Nancy H. The payroll tax and social-security finance, in MUSGRAVE, Richard (Org.). Broad-based taxes: new options and source. Baltimore/London: Johns Hopkins University, 1973, p. 87. $15 \mathrm{http} / / / \mathrm{www} 2$.anfip.org.br/publicacoes/livros/includes/livros/arqs-pdfs/desoneracao_folha_2012.pdf. p. 92. Acesso em 19/04/2014, às $23 \mathrm{~h}$.
} 
jurídica desta espécie tributária, haja vista se tratar de tema sobre o qual doutrina ${ }^{16} \mathrm{e}$ jurisprudência ${ }^{17}$ se dedicaram por longa data.

O tributo, de forma tradicional, sempre foi compreendido a partir do conceito legalmente previsto no CTN, art. 3:

Art. $3^{\circ}$ Tributo é toda prestação pecuniária compulsória, em moeda ou cujo valor nela se possa exprimir, que não constitua sanção de ato ilícito, instituída em lei e cobrada mediante atividade administrativa plenamente vinculada.

E, nesta linha, a natureza jurídica do tributo era analisada seguindo os ditames do CTN, art. 4:
Art. $4^{\circ}$ A natureza jurídica específica do tributo é determinada pelo fato gerador da respectiva obrigação, sendo irrelevantes para qualificá-la: I - a denominação e demais características formais adotadas pela lei; II - a destinação legal do produto da sua arrecadação.

Assim, os tributos teriam como fonte de distinção somente o fato gerador descrito na hipótese de incidência tributária, repercutindo no reconhecimento de três espécies tributárias, nos termos do CTN, art. $5^{\circ}$ : imposto, taxa e contribuição de melhoria.

Entretanto este cenário nunca foi pacífico diante das contribuições sociais previdenciárias $^{18}$, sendo que somente com a edição da Constituição Federal de 1988 os contornos da exação passaram a ter alicerce mais firme ${ }^{19}$, permitindo-se claramente diferenciar as contribuições sociais previdenciárias por um atributo não permitido na redação do CTN, art. 4: a destinação.

\footnotetext{
${ }^{16}$ Ver os trabalhos de MELO, J.E.S. de. Contribuições sociais no sistema tributário. São Paulo: Malheiros, 2000; GRECO, M.A. Contribuições: uma figura sui generis. São Paulo: Dialética, 2000; SPAGNOL, W.B. As contribuições sociais no direito brasileiro. Rio de Janeiro: Forense, 2002; SOUZA, R.C. Regime jurídico das contribuições: São Paulo: Dialética, 2002; TOMÉ, F.D.P. Contribuições para a seguridade social à luz da Constituição Federal. Curitiba: Juruá, 2002.

${ }^{17} \mathrm{O} \mathrm{STF}$, no passado, considerou que as contribuições sociais haviam deixado de ser tributos por terem sido retiradas da EC 1/69 pela EC 8/77 (RE 148.754). No entanto, com o advento da Constituição de 1988, as contribuições voltaram a integrar o sistema tributário, conforme foi debatido no RE 146.733, ocasião em que foi reconhecida a sua natureza tributária, sendo este o posicionamento vigente até os dias de hoje.

${ }^{18}$ No presente parecer não abordaremos o histórico das contribuições sociais ou mesmo pelas seis teorias que buscaram explicar a sua natureza (Teoria do Prêmio de Seguro; Teoria do Salário Diferido; Teoria do Salário Social; Teoria do Salário Atual; Teoria Parafiscal; Teoria da exação sui generis e Teoria Fiscal), pois já reconhecida a natureza juridical de tribute pelo Supremo Tribunal Federal. Contudo, para os que desejarem recomenda-se a leitura da obra: JUNIOR, Nicolau Konkel. Contribuições Sociais: doutrina e jurisprudência. São Paulo: Quartier Latin, 2005.

${ }^{19}$ Destaque-se que não se está afirmando a inexistência de previsão das contribuições previdenciárias nos textos constitucionais anteriores, mas somente que as características tributárias destas ficaram mais fortes com a Constituição de 1988.
} 
Esse diferencial entre as contribuições e os impostos foi asseverado no texto constitucional, deixando ao imposto a vedação de conteúdo finalístico (art. 167, IV) e às contribuições a compulsoriedade deste (art. 149).

Em termos práticos, houve a constitucionalização do conceito de tributo, o qual deixou de ser analisado somente à luz do fato gerador para, atendendo os preceitos do Estado de Bem Estar Social que revisitou o sistema tributário brasileiro, também a observar a destinação.

Neste sentido cumpre destacar as palavras de Misabel Abreu Derzi (1977, p. 598-599):

A Constituição de 1988, pela primeira vez, cria tributos finalisticamente afetados, que são as contribuições e os empréstimos compulsórios, dando à destinação que lhe é própria relevância não apenas do ponto de vista do Direito Financeiro e Administrativo, mas igualmente de Direito Tributário.

$\mathrm{E}$, justamente por isso

o contribuinte pode opor-se à cobrança de contribuição que não esteja afetada aos fins, constitucionalmente admitidos; igualmente poderá reclamar a repetição do tributo pago, se, apesar da lei, houver desvio quanto à aplicação dos recursos arrecadados. É que, diferentemente da solidariedade difusa ao pagamento de impostos, a Constituição prevê a solidariedade do contribuinte no pagamento de contribuições e empréstimos compulsórios e a consequente faculdade outorgada à União de instituí-los, de forma direcionada e vinculada a certos gastos. Inexistente o gasto ou desviado o produto arrecadado para outras finalidades não autorizadas na Constituição, cai a competência do ente tributante para legislar e arrecadar.

A afirmação acima encontra respaldo na Constituição de 1988, art. 149. Fato que veio a ser reconhecido pelo Supremo Tribunal Federal quando, ao analisar a figura das contribuições sociais previdenciárias à luz, primeiramente, do conceito legal de tributo insculpido no $\mathrm{CTN}$, art. 3 e, $\log$ a a seguir à luz do conceito constitucional do tributo, asseverou no RE 138284/CE (Pleno, rel. Min. Carlos Velloso, j. 01/07/1992, DJ 28/08/1992, p. 13456) e no RE 556664/RS (Pleno, rel. Min. Gilmar Mendes, j. 12/06/2008, DJe 13/11/2008) tratarem-se as contribuições sociais previdenciárias de tributos em conformidade com o conceito constitucional deste, qual seja, o de que além da prática de um fato gerador deve-se analisar a destinação constitucional da imposição legal para definir a natureza jurídica tributária da exação ${ }^{20}$.

\footnotetext{
${ }^{20}$ Para maiores esclarecimentos sobre o conceito constitucional de tributo e a repercussão deste na natureza jurídica das contribuições sociais, ver DI SANTI, Eurico; CAHAL, Vanessa. O conceito de tributo. In Direito Tributário e Finanças Públicas. São Paulo: FGV, 2012.
} 
Destinação assegurada pela Constituição de 1988, art. 195, caput com a ressalva do ato das disposições constitucionais transitórias (ADCT), art. 76, no sentido de custear a previdência pública, seja na modalidade do servidor público (contribuição previdenciária do servidor público), seja na do regime geral (INSS).

Pacificada a natureza tributária das contribuições sociais previdenciárias com o elemento destinação como principal característica, resta cristalino que se trata de obrigação compulsória sujeita a todos os princípios tributários.

\subsubsection{Cunho finalístico das contribuições sociais no STF}

A partir do conceito constitucional de tributo aplicado às contribuições sociais previdenciárias, resta-nos perquirir então qual o fator gerador e o conteúdo finalístico da exação.

Sem pretender exaurir o debate sobre o tema do fato gerador da contribuição social previdenciária, em razão da grande controvérsia deste ${ }^{21}$, tem-se que a Constituição de 1988, art. 195 elegeu a base de cálculo da exação como sendo a folha de salários e demais rendimentos do trabalho pagos ou creditados, a qualquer título, à pessoa física que lhe preste serviço, mesmo sem vínculo empregatício.

A Lei 8.212/91 regulamentou a disposição constitucional em dois momentos, no art. 22 como contribuição patronal, e no art. 28 como contribuição do segurado.

Extrai-se da leitura de ambos os dispositivos a palavra remuneração como base da incidência, o que remete a um outro dispositivo constitucional o art. 201, § 11:

$\S$ 11. Os ganhos habituais do empregado, a qualquer título, serão incorporados ao salário para efeito de contribuição previdenciária e conseqüente repercussão em benefícios, nos casos e na forma da lei.

Aplicando-se o conceito constitucional de tributo às contribuições sociais previdenciárias temos que a premissa objetiva para que incida contribuição previdenciária patronal ou do segurado sobre a remuneração deste é a respectiva e efetiva repercussão desta em benefício previdenciário.

Neste sentido a jurisprudência do STJ é mais do que pacífica, com destaque para o seguinte excerto do voto do Min. Napoleão Nunes Maia Filho:

\footnotetext{
${ }^{21}$ Em especial entre aqueles que confundem o fato gerador (exercício de atividade laboral remunerada) com a base de cálculo.
} 
23. Esse foi um dos fundamentos pelos quais se entendeu inconstitucional a cobrança de Contribuição Previdenciária sobre a gratificação pelo exercício de Função Comissionada. E, ao meu sentir, é mais uma razão para se concluir pela não incidência da Contribuição Previdenciária sobre as verbas ora em discussão, uma vez que não há a incorporação desses benefícios à aposentadoria.” (STJ. REsp 1.322.945 / DF. DJe 08.03.13)

E o Superior Tribunal de Justiça nada mais fez, como reconheceu a Min. Eliana Calmon na PET 7.296, do que seguir o posicionamento do Supremo Tribunal Federal, com destaque a:

[...] 2. A jurisprudência do Supremo Tribunal Federal firmou-se no sentido de que somente as parcelas que podem ser incorporadas à remuneração do servidor para fins de aposentadoria podem sofrer a incidência da contribuição previdenciária. (AI 710.361/MG, Rel. MINISTRA CARMEN LÚCIA, PRIMEIRA TURMA, DJ 08/05/2009)

Poderiam ser colacionadas outras inúmeras decisões do Supremo Tribunal Federal no sentido do cunho finalístico das contribuições sociais previdenciárias, mas optou-se por trazer à colação as mais claras e fortes para justificar a conclusão a que se pretende chegar.

Neste sentido vejamos os debates traçados no julgamentos das ADINs 2.0102/DF e 3.105-8, ambas sobre a contribuição dos servidores públicos inativos.

Na ADIn 2.010-2 manejada em face da EC 20/98 o Min. Celso de Mello deixou clara a posição do STF em seu voto na concessão da Medida Cautelar ao afirmar:

[...] Se é certo, portanto, que nenhum benefício ou serviço da seguridade social será criado, majorado ou estendido sem a precedente fonte de custeio total $(\mathrm{CF} / 88$, art. 195, paraágrafo 5$)$, não é menos exato que também não será lícito, sob uma perspectiva estritamente constitucional, instituir ou majorar contribuição para custear a seguridade social sem que assista, àquele que é compelido a contribuir, o direito a novos benefícios ou a novos serviços.

A referida ADIN não teve seu mérito julgado tendo em vista a superveniência da EC 41/03, logo houve "perda de objeto".

Sobreveio então a ADIN 3.105-8 em face da EC 41/03 em que a relatora, a então Min. Ellen Gracie afirmou: "contribuição previdenciária é tributo que exige estrita vinculação causal entre contribuição e benefício".

O voto da Ministra pela inconstitucionalidade da contribuição dos inativos não foi acompanhado pelo colegiado da Egrégia Corte, tendo sido nomeado relator o 
Min. Cezar Peluso, que reforçou o elemento nuclear das contribuições sociais previdenciárias:

O fato gerador e a base de cálculo não bastam para identificar e discernir as contribuições, as quais, como já acentuamos, ex vi das regras conformadoras do regime constitucional próprio, inscritas nos art. 149 e 195, caracterizam-se sobretudo pela finalidade e destinação [...]

Em seu voto o Ministro Cezar Peluso reconheceu a constitucionalidade da exação dos servidores públicos inativos porque incidente sobre o que ultrapassasse o teto do regime geral, atendendo assim à isonomia na medida em que

[...] 22. Os servidores públicos aposentados antes da edição da EC 41/03 não estão à margem do grupo socioeconômico conexo à finalidade da previdência social; antes, porque sua subexistência pessoal depende diretamente dos benefícios pagos, interessa-lhes sobremodo a manutenção do sistema.

A circunstância de estarem aposentados não lhes retira de per si a responsabilidade social pelo custeio, senão que antes a acentua e agrava, à medida que seu tratamento previdenciário é diverso do reservado aos servidores da ativa. Enquanto os primeiros se aposentaram com proventos integrais, os que ingressarão após a Emenda, poderão pelo regime público (art. 40, parágrafo 4), receber, no máximo, o valor correspondente a 10 salários mínimos, com abstração do montante dos benefícios percebidos à época da aposentadoria. E, porque os servidores só entraram a contribuir desde a Emenda Constitucional 3/93, existem, ou podem existir, servidores agora inativos com proventos equivalente à última remuneração sem nunca terem contribuído para o custeio do sistema.

E segue o Ministro relator explicando porque os proventos de aposentadorias/pensões excedentes ao teto do regime geral são passíveis de incidência de contribuição previdenciária, justamente para atender o equilíbrio econômico e atuarial diante dos inúmeros benefícios concedidos sem fonte de custeio, reforçando assim a relação de que os beneficiários que passaram a ter de contribuir sobre o excedente não estavam sendo sujeitos passivos de impostos, na medida em que a natureza jurídica da contribuição se manteve inalterada pelo destino.

Em outras palavras os servidores inativos afetados pela EC 41/03 estariam no grupo dos não limitados ao teto do RGPS com a opção do FUNPRESP, mas no dos que gozariam de integralidade e/ou paridade e valor superior ao do INSS, sem a adoção do cunho contributivo compulsório que adveio com a EC 3/93 ratificada pela EC 20/98 no sentido de aposentadoria por tempo de contribuição e não mais por tempo de serviço.

Assim, o STF reforçou a concepção do princípio da solidariedade e da justa tributação, ao mesmo tempo em que pontuou a análise da solidariedade do individual 
para o grupo, dispondo sobre o papel solidário do contribuinte, com a necessária repercussão de benefício previdenciário a favor deste, sob pena da contribuição previdenciária, no caso concreto, alçar contornos de imposto.

Isto porque, a contribuição do inativo se justifica pela repercussão no benefício deste que não necessariamente verteu contribuição ou se o fez, não foi em valor suficiente para custear seu benefício - note-se que o equilíbrio econômico e atuarial só vieram para o sistema jurídico brasileiro como princípios norteadores do direito previdenciário, com a EC 41/03 para os servidores e EC 20/98 para o RGPS - , tanto que para os novos servidores o cenário será diferente, justamente porque sua contribuição será limitada ao teto do RGPS, bem como seu benefício.

Sopesando-se o julgamento de ambas as ADIs, isto sem falar em toda jurisprudência de custeio do STF, tem-se que o próprio Tribunal assevera a necessidade de que a contribuição previdenciária repercuta em benefício para o cidadão contribuinte diretamente, não se confundindo com a contribuição social geral (PIS/COFINS/CSSLL, entre outras) que revertem do coletivo para o coletivo.

Assim, conforme reiteradamente reconhecido pelo STF, contribuições sociais possuem natureza jurídica de tributo e, mais, com destinação vinculada. Elemento que as diferencia dos impostos.

Passa-se a examinar, agora, o argumento referente ao dever de fiscalização que recai ao INSS.

\subsection{Do dever de fiscalização}

Caso restassem superados o argumentos trazidos nos itens anteriores e se entendesse como indispensável para a manutenção da aposentadoria especial a contribuição SAT por parte da empresa, no caso do seu inadimplemento, estaríamos diante de uma falha da autarquia referente a fiscalização.

Esta premissa encontra fundamento no Código Tributário Nacional, que em seus artigos 119 e 120 dispõem sobre o sujeito ativo da relação tributária:

Art. 119. Sujeito ativo da obrigação é a pessoa jurídica de direito público, titular da competência para exigir o seu cumprimento.

Art. 120. Salvo disposição de lei em contrário, a pessoa jurídica de direito público, que se constituir pelo desmembramento territorial de outra, subroga-se nos direitos desta, cuja legislação tributária aplicará até que entre em vigor a sua própria. 
Sujeito ativo, portanto é a pessoa titular da competência para exigir o cumprimento da obrigação tributária, ou seja, ao tratar-se do Seguro de Acidente de Trabalho (SAT), é o INSS esse sujeito ativo.

Já no que se refere ao encarregado pelo pagamento do tributo, este é definido como sujeito passivo, ou seja, a pessoa obrigada ao pagamento do tributo ou da penalidade tributária estabelecida em lei. Neste caso, ainda existe um desdobramento, porque tem-se o contribuinte, que é aquele com relação pessoal e direta com a situação prevista no fato gerador; e o responsável, que não tem relação pessoal e direta, mas que tem atribuída essa condição especial por força de lei.

Em que pese a evidência e a simplicidade destes conceitos, estes se fazem necessários, pois parecem ser ignorados pelo INSS. Diz-se isto porque no caso do SAT, a empresa é a responsável pela contribuição (art. 121, inciso II, CTN). Não se trata apenas de previsão legal (art. 22, inciso II, da Lei 8.213/91), mas também constitucional (art. 195, I, “a” e II).

Já à Previdência recaem os ônus pela fiscalização e para exigir o cumprimento da obrigação (artigo 119, do CTN). Não bastasse tal, ao se observar a Instrução Normativa da Receita Federal, IN RFB n 971/2009, tem-se que este órgão igualmente detém o poder de fiscalizar a regularidade pelo recolhimento do SAT, conforme expressamente prevê o artigo 288, inciso II:

\footnotetext{
Art. 288. A RFB verificará, por intermédio de sua fiscalização, a regularidade e a conformidade das demonstrações ambientais de que trata o art. 291, os controles internos da empresa relativos ao gerenciamento dos riscos ocupacionais, em especial o embasamento para a declaração de informações em GFIP, de acordo com as disposições previstas nos arts. 57 e 58 da Lei no 8.213 , de 1991.

Parágrafo único. O disposto no caput tem como objetivo:

I - verificar a integridade das informações do banco de dados do CNIS, que é alimentado pelos fatos declarados em GFIP;

II - verificar a regularidade do recolhimento da contribuição prevista no inciso II do art. 22 da Lei $\mathrm{n}^{\circ}$ 8.212, de 1991, e da contribuição adicional prevista no $\S 6^{\circ}$ do art. 57 da Lei ${ }^{\circ} 8.213$, de 1991 ;

III - garantir o custeio de benefícios devidos.
}

No que se refere ao segurado, o seu dever seria única e exclusivamente comprovar a exposição a agentes nocivos para fazer jus a aposentadoria especial. Cumpre lembrar que outrora bastava o exercício da profissão arrolada como nociva por algum motivo, mas agora exige-se a comprovação. 
Esta situação, inclusive, se assemelha ao dever da empresa de recolher a contribuição previdenciária de seus empregados e, com o advento da Lei $10.666 / 2003^{22}$, dos contribuintes individuais que lhe prestam serviços.

Ainda mais claro é o Decreto $\mathrm{n}^{\circ} 3.048 / 99$, em seu artigo 26, que expressamente determina a presunção pelo recolhimento:

Art. 26 - Período de carência é o tempo correspondente ao número mínimo de contribuições mensais indispensáveis para que o beneficiário faça jus ao benefício, consideradas a partir do transcurso do primeiro dia dos meses de suas competências.

[...]

$\S 4^{\circ}$ - Para efeito de carência, considera-se presumido o reconhecimento das contribuições do segurado empregado, do trabalhador avulso e, relativamente ao contribuinte individual, a partir da competência abril de 2003, as contribuições dele descontadas pela empresa na forma do art. 216.

Assim tem-se inafastável o dever de fiscalização do INSS.

Por fim, há, ainda, o contido no Enunciado n 18 , do Conselho de Recursos da Previdência Social, que mesmo sabendo de sua baixa hierarquia, é uma posição já manifestada pelo INSS em âmbito administrativo:

Enunciado $\mathbf{n}^{\circ} 18$ - Não se indefere benefício sob fundamento de falta de recolhimento de contribuição previdenciária quando esta obrigação for devida pelo empregador.

Deste modo, se a própria Previdência Social reconhece que não pode o direito à aposentadoria ser afastado em razão de cumprimento da obrigação tributária pelo empregador, não restam dúvidas que deve ser assegurado o direito do cidadão em obter a aposentadoria especial ainda que não tenha ocorrido o efetivo recolhimento do adicional do SAT.

\footnotetext{
${ }^{22}$ Art. $4^{\mathbf{0}}$ - Fica a empresa obrigada a arrecadar a contribuição do segurado contribuinte individual a seu serviço, descontando-a da respectiva remuneração, e a recolher o valor arrecadado juntamente com a contribuição a seu cargo até o dia 20 (vinte) do mês seguinte ao da competência, ou até o dia útil imediatamente anterior se não houver expediente bancário naquele dia.

$\S 1^{0}$ - As cooperativas de trabalho arrecadarão a contribuição social dos seus associados como contribuinte individual e recolherão o valor arrecadado até o dia 20 (vinte) do mês subsequente ao de competência a que se referir, ou até o dia útil imediatamente anterior se não houver expediente bancário naquele dia.

$\S 2^{\underline{Q}}$ - A cooperativa de trabalho e a pessoa jurídica são obrigadas a efetuar a inscrição no Instituto Nacional do Seguro Social - INSS dos seus cooperados e contratados, respectivamente, como contribuintes individuais, se ainda não inscritos.

$\S 3^{\mathrm{o}}$ - O disposto neste artigo não se aplica ao contribuinte individual, quando contratado por outro contribuinte individual equiparado a empresa ou por produtor rural pessoa física ou por missão diplomática e repartição consular de carreira estrangeiras, e nem ao brasileiro civil que trabalha no exterior para organismo oficial internacional do qual o Brasil é membro efetivo.
} 
Dessa forma, afasta-se o argumento de que é preciso ter ocorrido a efetiva contribuição da empresa para o segurado ter o direito de receber os valores a que tem direito.

\subsection{A análise da questão sob o enfoque da análise econômica do direito}

Visando aumentar a compreensão do fenômeno jurídico com a utilização e aplicação de postulados econômicos, nasceu o movimento denominado Direito e Economia ou Análise Econômica do Direito (AED). Inicialmente, restrito a escola de Chicago, nos EUA, a AED ganhou força na segunda metade do século passado, quando ultrapassou as barreiras nacionais e obteve adeptos em todo o globo.

O seu manejo possibilitou aos juristas compreenderem melhor os efeitos das regras sobre as pessoas. No entanto, em que pese os benefícios proporcionados pela AED, sua aceitação na doutrina jamais foi unânime. Seus críticos, como Dworkin (2000, p. 351) temiam que este movimento causasse uma "economização do direito". Basicamente, a corrente desfavorável à utilização da AED centra suas atenções em textos antigos de Posner, aduzindo que a premissa central do Direito e Economia seria a "maximização da riqueza" (DERZI; BUSTAMANTE, 2013, p. 328).

No entanto, há que se destacar que a AED é um movimento, portanto não estático e que evoluiu desde os seus primeiros apontamentos, especialmente com as lições trazidas por Ronald Coase, Oliver Williamson, Douglas North, Robert Cooter, Thomas Ullen. Assim sendo, não está restrita ao utilitarismo ou a eficiência, mas aborda questões de como as instituições influenciam as pessoas em seus comportamentos, ou, ainda, da relação existente entre mercados, direito e economia.

Ademais, em âmbito nacional a doutrina também já possui relevantes pensadores, dentre os quais se destacam Ivo Gico Teixeira Junior, Bruno Meyerhof Salama, Raquel Sztajn, Décio Zylberstajn, Armando Castelar Pinheiro e Jairo Saddi.

Feitas estas considerações introdutórias, acreditamos que os postulados fornecidos pela AED trazem mais benefícios do que perdas, sendo, inclusive, capaz de evidenciar comportamentos oportunistas que afetam negativamente o direito.

Comportamentos oportunistas seriam ocasiões em que uma das partes busca maximizar o seu interesse pessoal, em detrimento de uma alternativa melhor para o coletivo, ou seja, aquele comportamento baseado na astúcia (WILLIAMSON, 1985). 
Feitas estas considerações introdutórias, no presente estudo trabalharemos com os conceitos da seleção adversa e do risco moral.

A seleção adversa, nas palavras de Salainé (2005, p. 13) ocorre quando as características do agente não podem ser perfeitamente observadas pelo principal ${ }^{23}$. Em outros termos, fala-se em seleção adversa quando uma das partes, entendida como a principal, não consegue reunir informações suficientes para examinar o negócio jurídico de forma plena antes de a relação iniciar. Este termo advém de um fenômeno tradicionalmente utilizado no mercado de seguros: as empresas oferecem tarifas moldadas para o homem médio, ou seja, para aqueles que oferecem um risco comum. Todavia, este preço estipulado somente será atrativo para quem oferece grandes riscos, o que fará com que a empresa perca dinheiro.

Outro exemplo de seleção adversa e de assimetria de informação ocorre na relação credor-tomador, como ensina Dos Reis (2012, p. 10). O autor destaca que o tomador, pessoa que busca um empréstimo bancário, sabe exatamente sobre a condição de sua saúde financeira, informação que o banco não tem. A instituição bancária, por sua vez, poderia fazer longos questionários de todos aqueles que desejam obter um crédito, mas isto iria lhe acarretar em um aumento de custo de triagem. Assim sendo, esta situação beneficia o "mau" tomador, eis que pode omitir do banco sua real situação financeira, a fim de que obtenha um contrato favorável, com taxas de juros menores.

Nesta linha de raciocínio, Laffont e Martimort (2002, pp. 28-29), entendem que tudo isto gera custos para o principal $^{24}$, que, por sua vez, irá voltar seus esforços para obter informações dos outros agentes e não para atingir eficiência na produção ou no nível de utilidade (KLEIN, 2013, p. 125).

Diante deste panorama, chega-se ao risco moral, momento em que a assimetria de informação leva a uma fuga do cumprimento do contrato (KLEIN, 2013, p. 128).

\footnotetext{
23 "We use the term 'adverse selection when a characteristic of the Agent is imperfectly observed by the Principal. This term comes from a phenomenon well know to insures: If a company offers a rate tailored only to the average-risk population, this rate will attract only the high risk population and the company will therefore lose money."

24 'In order to reach an efficient use of economic resources the contract must elicit the agent's private information. This can only be done by giving up some information rent to the privately informed agent. Generally, this rent is costly to the principal. This information cost just adds up to the standard technological cost of performing the task and justifies distortions in the volume of trade achieved under asymmetric information. The allocative and the informational roles of the contract generally interfere."
} 
Dos Reis (2012, p. 13) assevera que o “[...] risco moral corresponde as ações de um indivíduo, que influenciam no cumprimento do contrato e que não são diretamente observáveis pelo principal".

Outra definição é trazida por Macho-Stadler e Péreza-Castrillo (2001, p. 9), os quais acreditam que o risco moral ocorre quando a ação do agente não é possível de ser verificada ou quando o agente possui informação privada somente após o início da relação. O risco moral ocorre, portanto, quando as partes tem a mesma informação quando a relação é estabelecida, mas a partir do momento em que o contrato é assinado, o principal não apresenta condições de controlar a ação ${ }^{25}$.

Esta assimetria informacional, obviamente, afeta a eficiência de qualquer relação e pode estar sendo utilizada pelo INSS para eleger uma conduta de não fiscalizar as empresas para não ter que arcar com os custos decorrentes da concessão do benefício de aposentadoria especial.

Diz-se isto porque caso o ARE 664335 seja julgado procedente e entender que a mera informação contida no formulário PPP acerca da eficácia do EPI é suficiente para afastar o direito à aposentadoria especial, não terá a Previdência Social incentivos para fiscalizar a empresa.

Em outros termos: estará criado um cenário favorável ao "mau empregador", que não investe em segurança do trabalho, expõe seus empregados a riscos e preenche de forma incorreta o formulário. Se não houver fiscalização por parte do INSS, estará aberto o caminho para a ilegalidade, sendo o segurado o maior prejudicado desta conduta.

Diz-se isto porque a Previdência Social não terá qualquer estímulo em fiscalizar o "mau empregador": a informação de que o EPI é eficaz lhe é benéfica. Ato contínuo não irá conceder o benefício de aposentadoria especial.

Assim procedendo, o INSS terá um meio de reduzir os seus custos de transação, isto é, as suas despesas com benefícios previdenciários. Como qualquer agente econômico, a Previdência também é movida por sua racionalidade e visa

\footnotetext{
${ }^{25}$ A moral hazard problem exists when the agent's action is not verifiable, or when the agent receives private information after the relationship has been initiated. In moral hazard problems the participants have the same information when the relationship is established, and the informational asymmetry arises from the fact that, once the contract has been signed, the principal cannot observe (or cannot verify) the action (or the effort) of the agent, or at least, the principal cannot perfectly control the action." (MACHO-STADLER; PÉREZ-CASTRILLO, 2001, p. 9).
} 
maximizar o seu interesse pessoal. Desta forma, como o dinheiro é um recurso escasso, nada mais óbvio que busque meios para atenuar os seus gastos.

De forma idêntica, pensará o empresário: ao preencher o formulário PPP com a informação da eficácia do EPI, conseguirá reduzir a sua contribuição social do SAT, por meio da aplicação do FAP.

Não pode o Poder Judiciário, em especial a suprema corte, criar estas situações que visam desestabilizar a cooperação entre os agentes. Diante disto, caso seja julgado favorável o ARE664335 estará criada uma situação de eficiência de Pareto para a Previdência e para os empregadores.

De acordo com Vilfredo Pareto, a eficiência econômica ocorre quando a melhora da situação de um indivíduo necessariamente representa um abalo na situação de outro. Por conta disso, é considerada individualista por duas razões: a primeira, porque se volta ao bem-estar individual e a segunda, porque "[...] só conta com a percepção que cada pessoa tem do seu bem-estar" (BITTENCOURT, 2011, p. 31-32).

Do ponto de vista econômico, será bastante eficiente para o INSS e para os empregadores, a procedência do ARE 664335. No entanto, restará prejudicado o direito social do segurado à aposentadoria especial.

Conforme destacado no início deste trabalho, os direitos sociais de segunda dimensão representam em um agir do aparelho estatal e surgiram como um meio de os indivíduos assegurarem a liberdade perante o Estado.

Neste contexto, a procedência do ARE 664335 representaria um retrocesso ao nosso país e colocará em xeque a aposentadoria especial.

\section{Considerações finais}

Diante das considerações acima tecidas, conclui-se que:

1 - A previdência social, espécie do gênero seguridade social, possui três fonte de custeio, quais sejam: a) recursos provenientes dos orçamentos da União, dos Estados, do Distrito Federal e dos Municípios, b) contribuições sociais; e c) outras que oportunamente venham a ser criadas.

2 - O princípio da precedência da fonte de custeio reside na impossibilidade de criar, majorar ou estender benefícios ou serviços sem observar a fonte de custeio. 
3 - A precedência da fonte de custeio atua no plano normativo, na manifestação legislativa e não na arrecadação e na fiscalização. Assim, a criação da precedente fonte de custeio operou-se com a edição da Lei 3.807/60, art. 69 e seguintes, tendo somente sido sucedida pela Lei 8.212/91. Ambas sempre dispuseram sobre o custeio geral dos benefícios previdenciários, tendo as Leis 8.212/91 e 8.213/91, art. 57 com a redação dada pela Lei 9.732/98 somente reforçado o custeio para alguns benefícios no sentido educativo em face das empresas que não zelarem pela segurança do meio ambiente laboral. Ratifica-se então que a Lei 8.212/91 com a alteração promovida pela Lei 9.732/98 só veio a prever reforço para o custeio das aposentadorias especiais, porque custeio sempre houve na incidência da contribuição social sobre a remuneração.

4 - As contribuições sociais constituem tributos, portanto estão sujeitos às regras tributárias, dentre as quais aquela estabelecida entre o sujeito ativo e o sujeito passivo.

5 - Nos termos da Constituição de 1988 (art. 195, I, “a”) a contribuição social destinada ao financiamento da aposentadoria especial fica a cargo da empresa, através de desconto na folha de salário.

6 - A relação jurídico tributária prevista na Lei $8.213 / 91$, art. $57, \S 6^{\circ}$, se opera entre o sujeito ativo União e o sujeito passivo empresa/empregadora/tomadora de serviço e não entre a União e o segurado. Desta feita se o sujeito ativo foi omisso no dever de fiscalização, tanto que o segurado vem a comprovar sua efetiva exposição ao risco, não pode este ser privado de direito reconhecido constitucionalmente pelo simples fato do descumprimento da obrigação tributária pelo empregador.

7 - Ao segurado recaem os ônus para comprovar o tempo especial junto a Previdência Social, nos termos da Lei 8.213/91, art. 57, $\S 3^{\circ}$; ao passo que a empresa tem o dever de verter a contribuição e, por fim, à Receita Federal recai a responsabilidade pela fiscalização, conforme expressamente determina a Instrução Normativa n. 971, da SRFB,, em seu artigo 288.

8 - A condição de hipossuficiente dos segurados em relação ao recolhimento de contribuições que lhes favoreçam restou reconhecida pelo Dec. 3.048/99, art. 26, $\S 4^{\circ}$, quando este determinou ser presumido o recolhimento de contribuições descontadas do segurados. Imaginemos, agora, na situação do adicional do SAT em que o segurado sequer toma conhecimento do recolhimento ou não deste, pois nem sofre o desconto para poder questionar a empresa. 
9 - Ainda que recolhido fosse o adicional do SAT que legalmente teria como destino custear as aposentadorias especiais, 20\% do arrecadado não seria aplicado no destino, desnaturando a própria natureza jurídica da contribuição social por intermédio da figura da Desvinculação de Recursos da União disposta no ADCT, art. 76, logo mais um elemento para ponderação quando se falar na suposta ausência de fonte de custeio.

11 - Infere-se a partir da natureza jurídica da aposentadoria especial enquanto regra e da precedência da fonte de custeio como princípio que aquela prevalece, haja vista sua eficácia decisiva, não dando margem ao intérprete fazer interpretação diversa daquela já estabelecida pelo texto constitucional. Assim, o direito à aposentadoria especial ou mesmo ao computo de tempo especial não pode ceder diante do princípio da precedência da fonte de custeio, sob pena de esvaziar o próprio direito.

12 - Caso fosse acolhido como presumidamente eficaz o EPI pela ausência de recolhimento do adicional do SAT, a autarquia previdenciária deveria ser obrigada a revisar todos os benefícios indeferidos de segurados que tiveram pela empresa o recolhimento do adicional; bem como a conceder de ofício aposentadoria especial ou conversão de tempo especial em comum para os empregados de empresas que recolheram a favor deste o adicional do SAT.

13 - A procedência do ARE 664335 criaria um ambiente de risco moral e seleção adversa, beneficiando os maus empregadores e à Previdência Social, que não terá estímulos de fiscalizar as empresas. Esta situação se assemelha ao ótimo de Pareto, em que o único prejudicado será o segurado, que praticamente não terá meios para obter o seu direito à aposentadoria especial.

\section{Referências bibliográficas}

ATALIBA, Gerado. Hipótese de incidência tributária. $6^{\mathrm{a}}$ edição. São Paulo: Malheiros, 2010.

ÁVILA, Humberto. Limites à Tributação com base na solidariedade social. In Solidariedade Social e tributação. GRECO, Marco Aurélio; GODOI, Marciano Seabra de (org.). São Paulo: Dialética, 2005.

BARROSO, Luís Roberto; BARCELLOS, Ana Paula de. A nova interpretação constitucional: ponderação, argumentação e papel dos princípios. In: LEITE, George 
Salomão (Org.). Dos princípios constitucionais: considerações em torno das normas principiológicas da Constituição. São Paulo: Malheiros, 2003.

BITTENCOURT, Maurício Vaz Lobo. Princípio da Eficiência. In: ; KLEIN, Vinicius; RIBEIRO, Marcia Carla Pereira (Coord.). O que é análise econômica do direito: uma introdução. Belo Horizonte: Fórum, 2011. p. 27-37.

BONAVIDES, Paulo. Curso de direito constitucional. São Paulo: Malheiros, 2003.

DERZI, Misabel Abreu Machado. Notas atualizadoras de Limitações Constitucionais ao Poder de Tributar. 7. a edição, de Aliomar Baleeiro. Rio de Janeiro: Forense, 1977.

DERZI, Misabel de Abreu Machado; BUSTAMANTE, Thomas da Rosa de. Rev. Fac. Direito UFMG, Número Esp. em Memória do Prof. Washington Peluso..., pp. 327 352, 2013.

DI SANTI, Eurico; CAHAL, Vanessa. O conceito de tributo. In Direito Tributário e Finanças Públicas. São Paulo: FGV, 2012.

DOS REIS, Victor Mauro Salomoni. Ensaios sobre seleção adversa e risco moral no mercado de crédito, 2012. 86 f. Dissertação (Mestrado em Economia) - Fundação Getúlio Vargas, 2012.

DWORKIN, Ronald. Uma questão de princípio. Tradução Luís Carlos Borges. São Paulo: Martins Fontes, 2000.

JUNIOR, Nicolau Konkel. Contribuições Sociais: doutrina e jurisprudência. São Paulo: Quartier Latin, 2005.

KLEIN, Vinícius. A economia dos contratos na teoria microeconômica: uma análise a partir do realismo crítico, 2013. 290 f. Tese (Doutorado em Economia) Universidade Federal do Paraná, 2013.

LAFFONT, Jean-Jacques; MARTIMORT, David. (2002). The Theory of Incentives:

MACHO-STADLER, Inés; PÉREZ-CASTRILLO, J. David (2001). An Introduction to the Economics of Information: incentives and contracts. $2^{\mathrm{a}}$ ed., New York: Oxford University Press.

MENDES, Gilmar Ferreira; COELHO, Inocêncio Mártires; BRANCO, Paulo Gustavo Gonet. Curso de Direito Constitucional. São Paulo: Saraiva, 2011.

RIBEIRO, Maria Helena Carreira Alvim. Aposentadoria especial: regime geral de previdência social. Curitiba: Juruá, 2013.

SALANIÉ, Bernard. (2005). The Economics of Contracts: primer. 2a ed., Cambridge: The MIT Press.

SARLET, Ingo Wolfgang. A eficácia dos direitos fundamentais. $9^{\mathrm{a}}$ edição. Porto Alegre: Livraria do Advogado, 2008. 
SCHAFER, Jairo Gilberto. Classificação dos direitos fundamentais. Do sistema geracional ao sistema unitário - uma proposta de compreensão. Porto Alegre: Livraria do Advogado, 2005.

SCHOUERI, Luís Eduardo. Introdução. Normas tributárias indutoras e intervenção econômica. Rio de Janeiro: Forense, 2005. the principal-agent model. Princeton: Princeton University Press.

WILLIAMSON, O. The economic institutions of capitalism. New York: The Free Press, 1985. 